Illinois State University

ISU ReD: Research and eData

Theses and Dissertations

6-27-2014

\title{
Outcome Variables of Childhood Sexual Abuse as Potential Risk Factors for Sexual Revictimization in Adulthood
}

Christine Renee Bowles

Illinois State University, crbowle@ilstu.edu

Follow this and additional works at: https://ir.library.illinoisstate.edu/etd

Part of the Clinical Psychology Commons

\section{Recommended Citation}

Bowles, Christine Renee, "Outcome Variables of Childhood Sexual Abuse as Potential Risk Factors for Sexual Revictimization in Adulthood" (2014). Theses and Dissertations. 210.

https://ir.library.illinoisstate.edu/etd/210

This Thesis is brought to you for free and open access by ISU ReD: Research and eData. It has been accepted for inclusion in Theses and Dissertations by an authorized administrator of ISU ReD: Research and eData. For more information, please contact ISUReD@ilstu.edu. 


\title{
OUTCOME VARIABLES OF CHILDHOOD SEXUAL ABUSE \\ AS POTENTIAL RISK FACTORS FOR SEXUAL \\ REVICTIMIZATION IN ADULTHOOD
}

\author{
Christine R. Bowles
}

48 Pages

August 2014

Childhood sexual abuse is a large problem, with research estimates indicating that between $16-25 \%$ of women have experienced sexual abuse at some point during their childhood (Dube et al., 2005; Gorey \& Leslie, 1997). Even more alarming is the data that suggests that women who have experienced childhood sexual abuse are between 2 to 11 times more likely to experience sexual assault as an adult than individuals with no past history of abuse (Messman-Moore \& Long, 2003). To help understand the complex and varied outcomes associated with childhood sexual abuse, Finkelhor and Browne (1985) developed a model conceptualizing the four main outcomes of CSA called the traumagenic dynamics, which include traumatic sexualization, powerlessness, betrayal, and stigmatization. These dynamics have been identified as the main sources of trauma resulting from CSA. This study examined all four traumagenic dynamics and their possible relationships with childhood sexual abuse and revictimization in adulthood. Traumatic sexualization was assessed using a measure of body dissatisfaction, powerlessness was conceptualized in terms of coping strategies employed by victims, 
betrayal was assessed by examining forgiveness of an abuser by the victim, and stigmatization was assessed by disclosure of abuse. Findings support literature which suggests that victims of childhood sexual abuse are at a higher risk of sexual revictimization in their first semester on a college campus when compared to non-abused participants. Additionally, this study found that victims of childhood sexual abuse reported higher rates of body image dissatisfaction and that body image dissatisfaction was related to the risk of sexual assault in the first semester on a college campus. 


\section{OUTCOME VARIABLES OF CHILDHOOD SEXUAL ABUSE AS POTENTIAL RISK FACTORS FOR SEXUAL REVICTIMIZATION IN ADULTHOOD}

CHRISTINE R. BOWLES

A Thesis Submitted in Partial Fulfillment of the Requirements for the Degree of MASTER OF SCIENCE

Department of Psychology

\section{ILLINOIS STATE UNIVERSITY}


OUTCOME VARIABLES OF CHILDHOOD SEXUALABUSE AS POTENTIAL RISK FACTORS FOR SEXUAL REVICTIMIZATION IN ADULTHOOD

CHRISTINE R. BOWLES

COMMITTEE MEMBERS:

Marla J. Reese-Weber, Chair

Corrine Zimmerman 


\section{CONTENTS}

CONTENTS

\section{CHAPTER}

I. PROBLEM STATEMENT 1

II. LITERATURE REVIEW 6

Traumagenic Dynamics Model 6

Traumatic Sexualization $\quad 7$

Powerlessness 10

Betrayal 14

Stigmatization $\quad 16$

Current Study 18

$\begin{array}{ll}\text { Hypotheses } & 21\end{array}$

$\begin{array}{lll}\text { III. } & 23\end{array}$

$\begin{array}{ll}\text { Participants } & 23\end{array}$

$\begin{array}{ll}\text { Materials } & 24\end{array}$

Hot Topics Questionnaire 24

The Child Sexual Abuse Questionnaire 25

The Sexual Experiences Survey 25

Trangression-Related Interpersonal

Motivations Inventory-12 (TRIM-12) 26

Brief COPE 26

The Body Shape Questionnaire (BSQ-8C) 27

$\begin{array}{ll}\text { Procedure } & 28\end{array}$

Time $1 \quad 28$

Time $2 \quad 29$ 
IV. RESULTS 31

$\begin{array}{lll}\text { V. DISCUSSION } & 36\end{array}$

$\begin{array}{ll}\text { REFERENCES } & 43\end{array}$ 


\section{CHAPTER I}

\section{PROBLEM STATEMENT}

Statistics about the prevalence of child sexual abuse (CSA) in the United States vary widely. Each year there is a concerted effort by the Children's Bureau of the U.S. Department of Health and Human Services to compile up-to-date statistics on child abuse in the nation. In the most recent report, the Children's Bureau (2011) identified 676,569 unique victims of child abuse, meaning that 9.1 out of every 1000 children in the U.S. had been abused. Of these victims, $9.1 \%$, or 61,567 children, were sexually abused. As discouraging as these statistics are, they do not even begin to accurately represent the rate of child sexual abuse in this nation. The above numbers represent only the cases reported by agencies which were then investigated and ruled as actual cases of abuse. Therefore these numbers do not represent the large number of abuse cases each year which do not come to the attention of professionals, leaving these rates vastly underestimated.

Although the 2011 DHHS estimates are helpful, the real rate of child sexual abuse is unknown because it is highly under-reported.

One effort to establish a more accurate set of statistics is the National Incidence of Child Abuse and Neglect (NIS-4), which occurs every decade. This report offers a more accurate estimate because not only does it includes investigated cases, but also cases screened out before investigation, as well as cases of children who were determined maltreated by community professionals. In the most recent report to Congress, the NIS-4 
(2010) reported that almost one fourth of all cases of abuse identified were sexual abuse cases. This data resulted in an estimated 135,300 victims of child sexual abuse during the collection period of 2005 and 2006. This report also noted that girls were 5 times more likely to be sexually abused than boys, with 3 in every 1,000 girls being sexually abused.

Another research method for estimating the prevalence of childhood sexual abuse uses community samples. One of the most comprehensive studies using this method involved conducting a telephone survey of children (ages 10-16) which gathered 2000 participant self-reports of whether or not they had experienced CSA (Finkelhor \& Dziuba-Leatherman, 1994). This survey revealed that $10.5 \%$ of the sample had experienced childhood sexual abuse (either attempted or completed CSA) (Finkelhor \& Dziuba-Leatherman, 1994).

Other research, which synthesized data from 16 different studies, estimated prevalence rates of CSA at $16.8 \%$ for women and $7.9 \%$ for men (Gorey \& Leslie, 1997). A recent study conducted in 2005 surveyed over 17,000 people and found that 25\% of women and $16 \%$ of men had experienced childhood sexual abuse (Dube et al., 2005). As illustrated here, the estimates of prevalence rates for CSA vary widely due to differing definitions of the criteria of CSA, research methods used, population sampled, and other factors. Despite these inconsistencies, one constant is that numerous children must endure the trauma of sexual abuse each year.

Unfortunately, for the victims of childhood sexual abuse the victimization is not always confined to childhood. Research indicates that survivors of childhood sexual abuse are more likely to be revictimized later in life than those who were not sexually 
abused as children (Messman \& Long, 2000; Polusny, Rosenthal, Aban, \& Follette, 2004; Reese-Weber \& Smith, 2011). One study found that victims of childhood sexual abuse were not only at higher risk for sexual assault or abuse later in life, but also for physical abuse, kidnapping and stalking (Widom, Czaja, \& Dutton, 2008).

Revictimization has long been a topic of interest, and early research found that of those who had experienced CSA before age 14,63\% were revictimized in the form of rape or attempted rape after age 14, compared to only $35 \%$ of non-abused participants (Russell, 1986). The finding that CSA is associated with an almost doubled risk of later sexual revictimization has been consistently supported in the literature, though the estimated effect varies from study to study due to differing definitions of CSA, populations sampled, and other variables. Revictimization risk estimates vary from $13.7 \%$ (Humphrey \& White, 2000) to 27\% (McGee et al., 2002). A meta-analysis on the topic found that victims of CSA are estimated to be between 2 and 11 times more likely to be revictimized as adults when compared with non-abused participants (MessmanMoore \& Long, 2003).

Because victims of CSA are more likely to be victimized later in life, CSA victims are important to target for early intervention to help prevent subsequent revictimization. However, the problem lies in identifying those most in need of intervention, as not all victims are later revictimized. Across the literature it has been shown that victims of CSA show a variety of symptoms and there is no unified syndrome that has been associated with child sexual abuse. One meta-analysis examined the outcomes of child victims and found that one third exhibited no symptoms, while the rest frequently reported fears, 
posttraumatic stress disorder, behavior problems, and poor self-esteem (Kendall-Tackett, Williams, Finkelhor, 1993.) This is an important topic for research, as the outcomes of sexual abuse vary on an individual basis just as the risk for revictimization does, which suggests that it may be certain outcome variables associated with CSA that put a child at risk for revictimization more than the general experience of CSA itself.

Of particular interest to this study is the occurrence of sexual assault on college campuses. The 2002 National Crime Victimization Survey (NCVS) identified 247,730 separate instances of sexual assault and found that the highest rates of sexual assault were reported by women aged 16-19 and 20-24. The average incoming freshman woman at a university is between the ages of 18-22, making this population at a higher risk for sexual assault. Additionally, some studies have found that university women in general are at a higher risk for sexual assault when compared to women of the same age who are not enrolled at a university (DeKeseredy \& Kelly, 1993; Fisher, Cullen, \& Turner, 2000; Koss, Gidycz, \& Wisniewski, 1987). Based on these statistics, this study aims to recruit incoming freshman women aged 18-22 due to the high instances of sexual assault which occur in these populations.

For the purposes of this study, childhood sexual abuse will be defined as any sexual contact which occurred before the age of 16 where the abuser was five or more years older than the victim, or any sexual contact before age 18 wherein the victim was forced or coerced to engage in any sort of sexual activity (meaning the victim did not view the encounter as consensual). Sexual victimization in the first semester of college is defined as any sexual act that the victim feels was nonconsensual in nature, which could 
include fondling, digital penetration, and oral, anal, or vaginal sex. 


\section{CHAPTER II \\ LITERATURE REVIEW \\ Traumagenic Dynamics Model}

Although there is no single defining syndrome emerging from childhood sexual abuse, Finkelhor and Browne (1985) have conceptualized a model involving four traumagenic dynamics that result from childhood sexual abuse. The dynamics identified are: (a) traumatic sexualization, (b) powerlessness, (c) betrayal, and (d) stigmatization. These dynamics were identified as the four main sources of trauma most often seen in victims of childhood sexual abuse and serve as a sort of categorical system for understanding the effects of such abuse. They are not narrowly defined variables, but rather broad categories that contain various outcome variables with common themes; many different variables can fit into each category. For example, traumatic sexualization can be conceptualized as higher sexual risk-taking or an aversion to sexuality altogether. Past research has conceptualized betrayal in terms of attachment theory, showing that the betrayal associated with CSA puts victims at a higher risk for developing maladaptive, anxious attachment styles (presumably due to not knowing who to trust after being betrayed by a prominent figure in their childhood). The current study proposed to examine betrayal in the context of victim forgiveness of an abuser.

This study aims to replicate the procedures from a previous study conducted by Reese-Weber and Smith (2011). These researchers examined variables in the context of 
the Traumagenic Dynamics Model and investigated their relationship to revictimization in the first semester of college. Reese-Weber and Smith identified potential outcome variables of childhood sexual abuse such as attachment anxiety, self-esteem, self-blame, and generalized perception of control and examined their connection to sexual victimization in adulthood. The current used the same framework, instead investigating new variables within the context of the Traumagenic Dynamics Model.

The current study aimed to examine one outcome from each category of the traumagenic dynamics: (1) Traumatic sexualization was conceptualized as a negative body image. (2) Powerlessness was measured in terms of coping strategies employed by victims (avoidance versus approach strategies). (3) Betrayal was conceptualized as the amount of forgiveness felt by a victim towards their abuser. (4) Stigmatization was assessed by determining how many people the victim has disclosed their abuse experiences to. The present study examined the relationship between these outcome variables and their possible connections to sexual victimization in order to better identify, and thus better aid, victims of CSA. Additionally, this study aimed to further examine the relationship between CSA and revictimization, hypothesizing that participants who reported childhood sexual abuse would also report higher rates of sexual vicitmization after their first semester of college than participants with no history of sexual abuse.

\section{Traumatic Sexualization}

Traumatic sexualization is the process whereby a child develops dysfunctional sexual tendencies due to their exposure to developmentally inappropriate sexual experiences over the course of their abuse. Individuals who experienced CSA often have 
distorted views of sexuality or learn inappropriate sexual behaviors. The effects of traumatic sexualization vary widely and range on a spectrum of completely avoiding anything sexual to a near obsession with sexuality. Research on the topic of traumatic sexualization manifesting in overly sexualized behaviors is plentiful, and supports the idea that CSA victims often engage in risky sexual behaviors that put them at higher risk for revictimization (Briere, 1995; Runtz \& Roche, 1999).

Previous research has not thoroughly examined the motivating factors behind the sexual-risk taking that many childhood sexual abuse victims exhibit. This study hopes to find a common link between traumatic sexualization and revictimization by identifying a potential outcome variable of CSA that may account for the sexual risk-taking: traumatic sexualization in terms of body image dissatisfaction.

Over the course of their abuse, CSA victims were sexual objects at the hands of their abusers. Because of this objectification, "the self as a sexual object becomes the central organizing principle" (Sanderson, 2006, pg. 310) as they develop, leading to a worldview which is preoccupied with sex and a self-image that revolves around sexuality. This overly-sexualized worldview is influenced by distorted sexual experiences and can result in distorted views of sexuality as well as a negative body image.

Body image is defined as, "the picture we have in our minds of the size, shape, and form of our bodies; and our feelings concerning the size, shape and form of our bodies" (Slade, 1988, p. 20). As Wenninger and Heiman (1998) point out, this definition contains two separate parts: a perceptual component and an attitudinal component. The perceptual component of body image deals with an individual's appraisal of the size and 
shape of their body. The attitudinal component is independent from how large or small someone thinks they are, and instead about how an individual feels about their appraisal of their size. When referring to body image, this study is concerned with the attitudinal component to body image, that is, their body esteem.

Research has found that experiences of childhood sexual abuse are associated with body image dissatisfaction. Kearney-Cooke \& Ackard (2000) recruited 1664 women who were then matched based on age and Body Mass Index. This study compared CSA victims to non-victims, finding that participants who reported childhood sexual abuse experiences had higher rates of a negative body image compared to their non-abused counterparts. In addition, Ratican (1992) found that CSA victims can react to their abuse with shame about their own body, leading to a negative body image and the possible development of eating disorders.

Research suggests that victims of sexual abuse are more likely to exhibit dysfunctional sexual behaviors, which refers to any sexual behaviors that are viewed as maladaptive, such as using sex as validation of oneself or to cope with distress (Briere, Elliott, Harris, \& Cotman, 1995; Briere \& Runtz, 1990; Briere \& Zaidi, 1989; Runtz \& Roche, 1999; Walser \& Kern, 1996). It makes sense to hypothesize from this data that someone who develops a negative body image after their abuse experiences may then use sex to cope with the distress resulting from their body dissatisfaction or even to feel attractive (as a successful sexual encounter validates them as a worthy sexual partner). There is some research supporting this hypothesis, as it has been shown that victims of childhood sexual abuse may become dependent on others for validation (Briere \& Elliott, 
1994), and sex may be one avenue to gaining this validation.

Many CSA victims may engage in sexual activity for validation and to cope with the distressing outcome variables associated with childhood sexual abuse, one of which may be a negative body image. The dysfunctional sexual behavior of victims of childhood sexual abuse has been connected to a larger than average number of sexual partners (Briere, 1995; Runtz \& Roche, 1999), and a higher number of sexual partners is positively correlated with revictimization as an adult, as shown in a twenty year longitudinal study of a community sample (Siegel \& Williams, 2001).

Although research supports the incidence of body image disturbances in those who have a past history of childhood sexual abuse, there is little to no research connecting this outcome variable of CSA to a risk for revictimization in adulthood. This study proposed to examine the relationship between body image satisfaction (as a factor of traumatic sexualization) on sexual victimization, hypothesizing that individuals reporting higher rates of dissatisfaction with their body would be more likely to be sexually victimized during their first semester of college when compared to those who reported lower rates of body image dissatisfaction.

\section{Powerlessness}

One aspect of childhood sexual abuse is a lack of power on behalf of the victim. Victims of CSA were children who were powerless to put an end to their abuse, and the experience of their abuse often highlighted how little power they had in certain situations. Instead of simply feeling powerless in sexual situations, the feeling can generalize to other areas of life as well, as "repeated experience with uncontrollable, unpredictable 
aversive events may lead to diminished generalized perception of control" (Foa, Zinbarg, \& Olasov-Rothbaum, 1992, p. 231).

Related to the idea of power is that of coping strategies. Coping strategies are the ways in which people handle stressful events and the distress resulting from them, coping strategies include specific behaviors as well as patterns of cognition (Lazarus \& Folkman, 1984). Many coping strategies have been identified, including those that are considered more adaptive, such as positive reinterpretation and growth, and others that are considered less adaptive, such as substance abuse. Coping strategies can be conceptualized as dispositional or time-limited. Dispositional strategies are considered almost like an aspect of personality in that they are the set coping strategies most often employed by the individual over the course of their lifetime and therefore the most likely strategies used in times of stress. Time-limited measurements of coping strategies instead focus on measuring how often the individual has used certain coping mechanisms within a certain period of time or in response to a certain stressor. This study will use the concept of dispositional coping as we are interested in examining how an individual's general coping strategies may vary due to a history of child sexual abuse as well as how general coping strategies may affect the risk for revictimization.

Research has also identified patterns of coping, two of which are avoidant coping strategies and approach strategies (Holohan \& Moos, 1987). These patterns form a spectrum of coping strategies that involve avoiding stressful events and the distress resulting from them (avoidant strategies) to actively engaging with the distress and painful thoughts associated with a traumatic event in order to overcome them (approach 
strategies). Avoidant strategies generally involve distancing oneself from the stressor in order to alleviate the resulting distress while approach strategies involve direct action on behalf of the individual to manage the distress resulting from the stressor (Roth \& Cohen, 1986).

According to the Transactional Model of Stress and Coping (Lazarus \& Cohen, 1977), when a person is faced with a potential threat, they appraise the situation. Primary appraisal occurs as a person sizes up the threat of the stressor, deeming it positive or negative, controllable or not. Secondary appraisal occurs when the individual examines their ability to influence or control the stressor, which is determined by evaluating the resources they have to cope with the event. An individual determines how to react to a stressor based on their appraisal of the situation. Situations that are appraised as something that is controllable (because the stressor is deemed not to be a threat, or they determine that they have they appropriate resources to handle it) are more likely to be dealt with using approach strategies. Approach strategies are used in the context of stressors that individuals have appraised as having the power to change. Stressors that are determined to be out of the control of the individual are more likely to be dealt with using avoidant coping strategies, as the individual feels that the stressor is not something they can manage except by avoiding it altogether. Avoidant coping strategies, in this sense, are used mainly for regulating emotions in the face of stressors that an individual deems themselves powerless to change.

As explained earlier, when victims of CSA are rendered powerless in childhood abuse situations, they may be more likely to generalize this feeling of powerlessness to 
their adult lives, and are more likely to appraise situations as out of their control and thus tap into avoidant, rather than approach, strategies for dealing with stressors. Research supports this idea, as it has been found that victims of childhood sexual abuse more often turn to coping methods traditionally labeled as maladaptive (avoidant strategies included) (Merrill, Thomsen, Sinclair, Gold, \& Milner, 2001) even as adults who had many years between their abuse and their assessment of coping styles. Of additional interest is that the use of avoidant coping strategies was associated with more negative psychological outcomes and poorer psychological adjustment as adults (Perrott, Morris, Martin, \& Romans, 1998; Shapiro \& Levendosky, 1999).

It is important to note that neither approach nor avoidant strategies are inherently better or worse. In fact, there is evidence that coping with traumatic events is a process that occurs in phases, with different coping methods being employed at different times over the course of the process (Burgess \& Holstrom, 1976). Conceptually, avoidant strategies may help CSA victims in the short-term, as they can temporarily reduce distress, but disengagement with the trauma may also impede processing of the trauma (Walsh, Fortier, \& DiLillo, 2010). However, research suggests that statically engaging in avoidant strategies may be detrimental, as integration and processing of the trauma are integral phases in the process of recovery and cannot occur in the context of avoidance (Walsh, Fortier, \& DiLillo, 2010).

Some research has supported this model and identified avoidant coping styles as maintaining trauma symptoms in CSA victims, which impeded psychological adjustment and was associated with a higher risk of revictimization in adulthood (Fortier et al., 
2009). Research in this area is sparse, though, and requires additional studies to corroborate the results. This study intended to investigate the relationship between coping strategies and experiences of childhood sexual abuse, hypothesizing that CSA victims would be more likely to utilize avoidant coping strategies and less likely to use approach coping strategies when compared to non-victims. This study also proposed to investigate the relationship between coping strategies and sexual victimization during the first semester of college, hypothesizing that individuals who generally utilized more avoidant and fewer approach coping strategies would be more likely to be sexually victimized than individuals who utilized fewer avoidance and more approach strategies.

\section{Betrayal}

Betrayal occurs during sexual abuse because children are harmed by someone they previously trusted (Finkelhor \& Browne, 1985). This betrayal can occur in several ways, as a child may feel betrayed by the abuser or they may also feel betrayed by family members who were unable to prevent the abuse. Incestuous abuse may result in higher feelings of betrayal as children realize that a family member on whom they relied has taken advantage of them.

One possible measure of betrayal would be through assessing the forgiveness a victim feels for their abuser. Forgiveness can be conceptualized either as an overarching personality trait (a tendency to forgive) or a response to a specific transgression. For the purposes of this study, forgiveness was conceptualized in terms of a response to the experience of being abused and, more specifically, with forgiveness toward the abuser. Forgiveness is conceptualized as the deliberate decision by the forgiver to let go of the 
negative emotions they have been harboring toward their offender (American Psychological Association, 2006). In this respect, forgiveness is different from reconciliation, and does not require that the forgiver make efforts to repair their relationship with the abuser. It is also important to note that forgiveness does not require the forgiver to condone the abuse in any way or excuse the abuser for their actions.

Forgiveness is highly situational. Research has found that the more severe and intentional a transgression is seen to be, the less likely that someone is to forgive the transgressor (Boon \& Sulsky, 1997; Girard \& Mullet, 1997). In other words, the amount of betrayal that is perceived by the victim is directly related to how likely they are to forgive their abuser. One could conceive of individuals high in forgiveness as feeling less betrayal (as they found the transgression easier to forgive) than those who are low in forgiveness and unable to forgive their offender (due to a more severe perception of the transgression, and thus, more betrayal).

Research supports the idea that forgiveness is an act of letting go, and has shown that victims who forgive their transgressors have reduced negative affect toward the individual after the act of forgiving (Ohbuchi, Kameda, \& Agarie, 1989). Additionally, victims feel more empathy towards their offenders after forgiving them (McCullough et al., 1997). One study by Ball (2010) examined a clinical population of women who had a history of trauma, specifically examining the effect of forgiveness on their psychological adjustment, finding that those who forgave their offenders reported less depression and anxiety and higher rates of self-esteem after forgiving. In fact, researchers have found that higher rates of forgiveness are overall correlated with more positive psychological 
well-being (McCullough, Pargament, \& Thoresen, 2000; Toussaint \& Webb, 2005).

Hence, those low in forgiveness may be experiencing less psychological adjustment and well-being, which may put them at higher risk for revictimization as adults. This study proposed to evaluate the relationship between forgiveness of an abuser and revictimization, hypothesizing that victims of childhood sexual abuse low in forgiveness (i.e. feeling more betrayal) would be more likely to be revictimized in their first semester of college than those high in forgiveness (feeling less betrayal).

\section{Stigmatization}

The last of Finkelhor and Browne's (1985) traumagenic dynamics is stigmatization, which is defined as "the negative connotations that are communicated to the child around the experiences and that then become incorporated" (p. 3) into the child's worldview. Stigmatization can occur in many ways, before, after, and during the abuse. Before the abuse, children can be aware of the stigma surrounding CSA through awareness of social taboos, as well as cultural and religious norms that communicate to them that such acts are deviant. During the abuse, stigmatization takes on many forms. Abusers may actively shame their victims, bestowing in them a sense of guilt or responsibility for the abuse. Abusers may also pressure their victims to keep the abuse secret, which reinforces the idea that the abuse is something to hide and be ashamed of, fostering a feeling of stigmatization in the child. Finkelhor and Browne (1985) point out that "keeping the secret of having been a victim of sexual abuse may increase the sense of stigma, since it reinforces the sense of being different" (p. 4). Similarly, disclosing the events of abuse may help to alleviate feelings of stigma if the victim is reassured that the 
abuse was not their fault, or if they learn from the disclosure that their experience is not unique.

The influence of stigma on disclosure is seen in many ways. For example, incest survivors generally experience more intense fears of consequences if anyone found out about their abuse due to the complicated family dynamics; in addition, increased stigma surrounding incest can reinforce the inclination to hide CSA experiences (Paine \& Hansen, 2002). This pattern is demonstrated in the literature, as incest survivors are less likely than non-incest survivors to disclosure their CSA experiences (Heshkowitz et al., 2005) and also less likely to report the abuser to the police (Arata, 1998).

Similarly, research has found that women are more likely to disclose than men due to a greater stigma associated with being a male victim of childhood sexual abuse. One study of 733 college students found that $71 \%$ of women had, at some point, disclosed their CSA to someone, while only $46 \%$ of men reported ever disclosing their experiences. These numbers support the idea that disclosure is influenced by stigma, as male victims often perceive more stigma surrounding CSA due to their fears of not being believed (as the rates of male CSA are much lower) or being labeled a homosexual (Alaggia, 2005; Holmes et al. 1997; Sorsoli et al., 2008) These reasons may explain why men are less likely to disclose their abuse experiences to others. Additionally, one study found that not only were men less likely than women to disclose their experiences, men were also more likely to receive negative reactions to their disclosure when compared to women. These negative reactions are possibly due to the higher stigma involved with being a male victim of CSA, which further encourages men not to disclose their abuse experiences 
(Ullman \& Filipas, 2005)

Research has shown that feelings of stigma are positively associated with longterm psychological distress (Coffey, Leitenberg, Henning, Turner, \& Bennett, 1996), suggesting that those who do not disclose may be at a higher risk for negative outcomes. Preliminary research on disclosure of CSA events shows that victims who never disclosed their abuse experiences with anyone as well as victims who delayed disclosure reported higher scores of psychological distress as well as posttraumatic stress disorder symptoms (Hebert, Tourigny, Cyr, McDuff, \& Joly, 2009).

The current study aimed to investigate the relationship between disclosure of abuse experiences and revictimization, hypothesizing that CSA victims who did not disclose their abuse experiences to at least one person (more stigmatization) would be

more likely to be revictimized in their first semester of college than CSA victims who did disclose their abuse experiences to at least one other person (less stigmatization)

\section{Current Study}

Childhood sexual abuse is a large problem, with research estimates indicating that between 16-25\% of women have experienced sexual abuse at some point during their childhood (Dube et al., 2005; Gorey \& Leslie, 1997). Even more alarming is the data that suggests that women who have experienced childhood sexual abuse are between 2 to 11 times more likely to experience sexual assault as an adult than individuals with no past history of abuse (Messman-Moore \& Long, 2003). To help understand the complex and varied outcomes associated with childhood sexual abuse, Finkelhor and Browne (1985) developed a model conceptualizing the four main outcomes of CSA called the 
traumagenic dynamics, which include traumatic sexualization, powerlessness, betrayal, and stigmatization. These dynamics have been identified as the main sources of trauma resulting from CSA. These dynamics serve as four broad categories under which a myriad of other variables can be categorized according to common themes. Recently, research has begun to examine how these negative outcomes of childhood sexual abuse help predict who is more likely to experience sexual victimization later in life. For example, Reese-Weber and Smith (2011) examined each of the four traumagenic dynamics and their connection to revictimization in adulthood, finding that attachment (as a factor of betrayal) was significantly correlated with revictimization in the first semester of college

Although certain outcome variables (such as attachment style) have been associated with an increased risk for revictimization (Reese-Weber \& Smith, 2011), there are many other variables whose relationship to childhood sexual abuse and revictimization have yet to be examined. This study proposed to use the same framework as Reese-Weber and Smith (2011), investigating new variables under the same model and identifying their connection to revictimization in adulthood. This study examined all four traumagenic dynamics and their possible relationships with childhood sexual abuse and revictimization in adulthood. Traumatic sexualization was assessed using a measure of body dissatisfaction, powerlessness was conceptualized in terms of coping strategies employed by victims, betrayal was assessed by examining forgiveness of an abuser by the victim, and stigmatization was assessed by disclosure of abuse.

Additionally, this study went further in that it aimed to examine two variables 
(body image and coping strategies) in both abused and non-abused populations, which served to identify a broader set of risk factors for sexual victimization in adulthood which is not confined only to survivors of CSA. The remaining two variables (forgiveness of an abuser and disclosure of abuse experiences) were examined by identifying potential outcomes of childhood sexual abuse as predictors of revictimization of CSA victims in adulthood.

This study aimed to recruit females on college campuses, as women aged 16-19 as well as aged 20-24 have previously been found to be at a higher risk for sexual assault when compared to either men or women of other age groups (NCVS, 2002). Additionally, there is reason to believe that women in college settings are actually at higher risk for sexual assault overall (DeKeseredy \& Kelly, 1993; Fisher, Cullen, \& Turner, 2000; Koss, Gidycz, \& Wisniewski, 1987). Since the average age of incoming freshman women at a university is between 18 and 22, we are attempting to recruit from this population due to their higher risk for sexual assault when compared to the general population, other age groups, as well as the opposite gender.

To gather this information, incoming female freshman students at a large Midwestern University were targeted for study. All incoming freshman who had indicated that they would like to participate in research were sent an e-mail inviting them to participate at the beginning of the fall semester (in early September). Participants received a link to the online survey, where, after giving their informed consent, were asked to complete a demographic survey as well as measures of coping strategies and body image. A questionnaire was also given to screen for experiences of childhood sexual 
abuse. Those who indicated that they had experienced some form of childhood sexual abuse were also asked to complete measures of forgiveness and disclosure about the abuse to others. At the beginning of the following semester (January 2014) participants were contacted again and asked to complete a survey to assess for any instances of sexual assault that occurred during their first semester of college.

Because of the lower rates of sexual assault (both in college and in childhood) among men coupled with the higher response rates of females to research invitations, this study was aimed only at incoming freshman women. Additionally, the data used in this literature review primarily dealt with female research participants, meaning the hypotheses made here were less relevant to male populations. Due to these factors, it was decided to concentrate on recruiting only female participants to ensure the integrity of this study.

\section{Hypotheses}

1. Participants who reported experiencing childhood sexual abuse would be more likely to be sexually victimized in their first semester of college than participants with no history of sexual abuse.

2. Traumatic Sexualization: (a) Victims of childhood sexual abuse would have higher rates of dissatisfaction with their bodies when compared to non-abused participants. (b) Individuals who had higher levels of body image dissatisfaction (more traumatic sexualization) would be more likely to be sexually victimized during their first semester of college when compared to participants who had lower levels of body image dissatisfaction (less traumatic sexualization). 
3. Powerlessness: (a) Victims of childhood sexual abuse would utilize avoidant coping strategies at higher rates than non-victims and approach coping strategies at lower rates than non-victims. (b) Individuals who utilized more avoidant coping strategies (less power) would be more likely to be sexually victimized in their first semester of college than participants who utilized fewer avoidant coping strategies (more power). (c) Individuals who utilized more approach strategies would be less likely to be sexually victimized during their first semester of college than participants who used fewer approach coping strategies.

4. Betrayal: Victims of childhood sexual abuse who had lower levels of forgiveness towards their abuser (more betrayal) would be more likely to be sexually victimized during their first semester of college when compared to victims of childhood sexual abuse who had higher levels of forgiveness towards their abuser (less betrayal).

5. Stigmatization: Victims of childhood sexual assault who had not disclosed their abuse experiences to at least one other person (more stigmatization) would be more likely to be sexually victimized in their first semester of college when compared to victims who had disclosed their abuse experiences to at least one person (less stigmatization). 


\section{CHAPTER III}

\section{METHOD}

\section{Participants}

Participants were recruited through Illinois State University's master list of students who have agreed to be solicited for research purposes. A mass e-mail was sent out to all incoming Freshman students by the university's registrar. In the first wave of data collection, during September, 196 participants (42 males and 154 females) completed the survey. In the second wave of data collection, during January, 91 participants (25 males and 66 females) completed the survey. The majority of participants were 18 years old at Time $1(91.3 \%)$ and at Time $2(57.1 \%)$. Regarding ethnicity at Time 1 and Time 2, the majority of participants were White/Caucasian (86\% at time $1,79.1 \%$ at time 2), with others identifying as Black/African American (4.1\%, 6.6\%), Hispanic Latino (4.7\%, 6.6\%), Asian American/Pacific Islander (1.6\%, 1.1\%), and Mixed Ethnicity $(3.6 \%, 6.6 \%)$.

The majority of participants were living in residence halls (95.9\% at Time 1, $96.7 \%$ at Time 2$)$, with the rest living with parents $(3.6 \%, 3.3 \%)$ or in an apartment with friends $(.5 \%, 0 \%)$. The majority of participants reported that their biological/adopted parents were currently married (73\% at Time $1,71.4 \%$ at Time 2$)$, with the rest reporting that their biological/adopted children were currently divorced $(20.4 \%, 19.8 \%)$ or that they 
were raised by a single parent $(6.6 \%, 7.7 \%)$. Regarding parental education levels, the majority of participants reported that their mother had attended four years of college (38.5\% at Time 1, 29.7\% at Time 2), with others reporting two years of college or less $(21 \%, 25.3 \%)$, a graduate degree or higher $(20 \%, 0 \%)$, a high school degree $(19.5 \%$, $22 \%)$, or some high school but no degree $(1 \%, 23.1 \%)$. There were similar findings regarding paternal education level, with the majority of participants reporting that their father had attended four years of college (35.4\% at Time 1, 22.2\%), with others reporting two years of college or less $(22.6 \%, 28.9 \%)$, a high school degree $(22.6 \%, 23.3 \%)$, a graduate degree $(15.9 \%, 0 \%)$ or some high school but no degree $(3.6 \%, 25.6 \%)$.

\section{Materials}

\section{Hot Topics Questionnaire}

The 50-item Hot Topics Questionnaire was originally created for a study by Reese-Weber and Smith (2011). This measure was modified to contain only 15 yes or no items that ask about a variety of life experiences, including five items about experiences of childhood sexual abuse and sexual victimization during adolescence and adulthood. This measure was used in Wave 1 of the study as a screening device, and participants who answered yes to any of the five critical items were identified as potential CSA victims and prompted to respond to additional questionnaires. These five critical items were: (a) Someone has sexually touched me in ways that made me feel uncomfortable, (b) Before the age of 16, I had a sexual experience with an individual five or more years older than myself (any sexual activity involving physical contact), (c) another person has coerced me to engage in sexual activity (intercourse, oral/anal sex, petting/fondling), (d) I 
have engaged in sexual activity (intercourse, oral/anal sex, petting/fondling) when I didn't want to because someone threatened to use physical force, and (e) I have been sexually assaulted.

\section{The Child Sexual Abuse Questionnaire}

The Child Sexual Abuse Questionnaire (Finkelhor, 1979) was used in Wave 1 of the study to gather information about childhood sexual abuse experiences prior to age 16 . This measure has 10 items asking about various aspects of abuse, including the age of victim and abuser, relationship to abuser, specific sexual acts encountered, whether threat was involved, and to whom the individual disclosed the abuse.

To measure disclosure, a dichotomous variable was created to indicate whether or not the participant has disclosed their experiences to any other individual. The number of individuals to whom participants have disclosed to was not considered nor was the outcome of the disclosure (in terms of the individual's reaction to the disclosure). Risin and Koss (1988) showed that this measure had good internal validity.

\section{The Sexual Experiences Survey}

The Sexual Experiences Survey (SES) is a 13-item measure with each item in a yes/no format. The SES was used at Wave 1 to assess sexual abuse/assault that occurred after age 16 but prior to beginning college. If participants answered yes to any of the critical items, they were classified as having been victimized as a minor and were asked to whom they disclosed the abuse. A dichotomous variable was created to indicate whether or not the participant has disclosed their experiences. 
The Sexual Experiences Survey was also used at Wave 2 in order to assess sexual victimization that occurred after participation in Time 1 of the study. Previous studies have shown good reliability for the measure $(\alpha=.75)$ when used this way (Reese-Weber \& Smith, 2011).

\section{Transgressions Related Interpersonal Motivations Inventory-12 (TRIM-12)}

The Transgressions Related Interpersonal Motivations Inventory-12 (McCullough, Root, \& Cohen, 2006) is a 12-item self-report measure of transgressionspecific forgiveness, which is broken down into two subscales: revenge motivations and avoidance behaviors. This instrument does not assess an individual's dispositional forgiveness (i.e., their tendency to forgive as a function of personality variables) but rather prompts individuals to think of a specific transgression and answer questions about their feelings towards the perpetrator of the offense. In this study, participants who reported at Wave 1 that they had experienced sexual abuse during childhood were prompted to think of their abuser and answer questions to measure their level of forgiveness towards the abuser using a Likert scale from $1=$ strongly disagree to $5=$ strongly agree. Representative items from the instrument include: "I am avoiding him/her," "I'm going to get even." Reliability data for the TRIM-12 has been found to be $\alpha=.92$ (McCullough, Rachal, Sandage, Worthington, Brown, Hight, 1998.) The present study found a total reliability for the measure to be $\alpha=.95$.

\section{Brief COPE}

The Brief COPE is a self-report questionnaire comprised of 28 items each rated along a 4-point Likert scale ( 1 = I haven't been doing this at all, $4=$ I've been doing this a 
lot) that queries participants about their most frequently utilized coping strategies.

Participants completed this measure during Wave 1 of this study. For the purposes of this study, the subscales were divided into two categories based on the approach and avoidance strategies. The following subscales are representative of approach coping methods: active coping, use of emotional support, use of instrumental support, positive re-framing, planning, and acceptance. The remaining subscales represent avoidance coping strategies: self-distraction, denial, substance use, behavioral disengagement, venting, humor, religion, and self-blame. Internal reliabilities for the subscales of the Brief COPE range from .50 to .90 alpha coefficients (Carver, 1997). In the present study, reliability data for the approach subscale was $\alpha=.85$ and $\alpha=.76$ for the avoidance subscale.

\section{The Body Shape Questionnaire (BSQ-8C)}

The Body Shape Questionnaire is a measure that assesses dissatisfaction with one's body and having a negative body image. Participants completed this measure during Wave 1 of the study. The 8 items are each rated along a 6-point Likert scale $(1=$ never, 6 $=$ always). A representative item from the instrument is: "Has seeing your reflection (e.g. in a mirror or shop window) made you feel bad about your shape?" This instrument has been shown to have good internal reliability, construct validity, and discriminant validity (Cooper et al., 1987; Rosen et al., 1996; Pook et al., 2002; Pook \& Tuschen-Caffier, 2004; Ghaderi \& Scott, 2004). There are several versions of this measure available, but the BSQ-8C, used in this study, has been demonstrated to be the most psychometrically 
sound version of the instrument (Pook, Tuschen-Caffier, \& Brahler, 2006). The current study found reliability of $\alpha=.93$ when using this measure.

\section{Procedure}

\section{Time 1}

Illinois State University allows all students to indicate whether they would like to be solicited via e-mail for research participation. This study used this list to send a mass e-mail to all incoming freshman who had indicated such a desire to participate in research. Upon opening the e-mail, participants were greeted with a message that explained that they were being invited to take part in an online study. The message explained that the requirements for participation were that the participant was both between 18-22 years old and a first-time, incoming freshman. Participants were told that if they met these requirements, they were welcome to participate in a study which consisted of completing online questionnaires that would take no more than one hour, that their participation was voluntary, and that all of their responses were confidential. A link to the survey was included in the e-mail. This mass e-mail was sent at the beginning of data collection (in early September), and again a week later as a reminder.

Upon clicking the link, participants were taken to an informed consent page that explained the risks and benefits of the study, as well as their rights as participants. Participants were told that clicking "Next" and continuing onto the survey was taken as their consent to participate, and that they were free to withdraw from participating at any time. The survey consisted of (a) a demographics questionnaire, (b) the Brief COPE, (c) The Body Shape Questionnaire 8C, and (d) the "Hot Topics" questionnaire. Those 
participants who indicated that they had experienced some form of sexual abuse during childhood or adolescence were also prompted to complete the CSAQ (which gathers information about sexual abuse prior to age 16), the Sexual Experiences Survey (which gathers information about nonconsensual sexual experiences after age 16), and the TRIM-12 (which is a measure of forgiveness toward the abuser).

After participation, individuals were directed to read a debriefing statement, which included contact information for Illinois State University Counseling Services as well as the PATH crisis hotline should they have felt distressed and needed to talk to someone. Additionally, the contact information for the researchers was provided should participants have questions about the research project itself.

\section{Time 2}

Unfortunately, participation in the second phase of data collection was very low, as only 6 participants completed the questionnaire in December when the email invitation was sent. This data was thrown out and another mass e-mail was sent at the beginning of the spring semester to all freshman in order to gather more data for Time 2. This e-mail contained a similar script as the first, inviting participants who were freshman between ages 18-22 to participate in a survey. Upon clicking the link to the survey, participants were again presented with an informed consent document that explained the risks and benefits of participating as well as their rights as participants. If they decided to participate, individuals were then prompted to complete a demographics form and the Sexual Experiences Survey, which was used to assess whether the participant has been sexually assaulted during the past semester. After the surveys were completed, 
participants were again given a debriefing statement, which contained contact information for ISU Counseling Services and PATH crisis hotline as well as the contact information for the researchers. Participants were assigned randomly generated ID numbers by the survey system, which were used to connect Time 1 and Time 2 data while protecting confidentiality. 


\section{CHAPTER IV}

\section{RESULTS}

Of the total participants at Time 1, 54 (27.6\%) indicated that they had experienced some form of childhood sexual abuse. There were 91 participants at Time 2. Of these, 14 individuals (15.4\%) reported being sexually assaulted in their first semester of college. Twenty-seven of the 91 participants at Time 2 had also completed Time 1 measures, with 11 individuals from the childhood sexual abuse group and 16 from the non-abused group. Of these 27 individuals, 3 (27.3\%) of the participants who had experienced childhood sexual abuse reported being sexually assaulted in their first semester of college while none of those in the non-abused group reported experiences of sexual assault.

Hypothesis one stated that participants who reported experiencing childhood sexual abuse would be more likely to be sexually assaulted in their first semester of college than participants with no history of sexual abuse. The probability of being sexually assaulted (assaulted or not) based on CSA group (CSA victim or non-CSA victim) was analyzed using a Chi-Square analysis. The probability of being sexually assaulted in the first semester of college was significantly different based on CSA group $x^{2}(1, N=27)=4.91, p=.03$. Those who had reported experiencing childhood sexual abuse were more likely to be sexually assaulted in their first semester of college. It is 
important to note that due to the small sample size used in this analysis two cells had an expected count of less than 5. Hypothesis one was supported.

Hypothesis 2a stated that victims of childhood sexual abuse would have higher rates of dissatisfaction with their bodies when compared to non-abused participants. An independent samples $t$-test was used to compare mean differences on body dissatisfaction rates between the two CSA groups (CSA victim and non-CSA victim). The results were not statistically significant, $t(165)=1.43, p=.15$. These results indicate that the hypothesis was not statistically supported.

Hypothesis $2 \mathrm{~b}$ stated that individuals who have higher levels of body image dissatisfaction would be more likely to be sexually assaulted during their first semester of college when compared to participants who have lower levels of body image dissatisfaction. An independent samples $t$-test compared mean differences on body dissatisfaction between the two groups (sexually assaulted or not). These results were not statistically significant, $t(26)=1.26, p=.22$. This hypothesis was not supported.

While hypotheses 2a was not statistically significant, follow-up exploratory analyses revealed differences in the clinical levels reported by these groups. Participants in the non-CSA group had a mean of $23.57(S D=11.08)$, which puts them in the clinical category of "mild concern with body shape", while the Child Sexual Abuse group had a mean of $26.07(S D=9.50)$, which falls into the clinical category of "moderate concern with body shape". 
Follow-up analyses for Hypothesis $2 \mathrm{~b}$ revealed the same trend of lacking statistical significance but indicating clinical significance. Those who had been assaulted reported a mean body dissatisfaction score of $34.30(S D=15.82)$, and those who had not been assaulted reporting a mean score of $25.20(S D=11.48)$. These results varied widely from each other, as the individuals who had been sexually assaulted fall into the highest clinical category of "marked concern with shape" while the non-assaulted individuals scored in the category of "mild concern with shape", which is the lowest clinical category (above "no concern with shape"). However, only three individuals had been assaulted in comparison to 24 who were not, so caution should be used when interpreting these findings.

Hypothesis 3a stated that victims of childhood sexual abuse would utilize avoidant coping strategies at higher rates than the non-abused group and approach coping strategies at lower rates than the non-abused group. Independent samples $t$-tests compared mean differences in frequency of coping strategies used between the CSA groups (CSA victim or non-CSA victim). The results were not statistically significant for approach coping strategies, $t(162)=.32, p=.75$, or avoidance coping strategies, $t(162)=$ $1.16, p=.25$. This hypothesis was not supported.

Hypothesis $3 b$ stated that individuals who utilize more avoidant coping strategies will be more likely to be sexually assaulted in their first semester of college than participants who utilize fewer avoidant coping strategies. An independent samples $t$-test compared mean differences on avoidant coping strategies between the two groups 
(sexually assaulted and non-assaulted). The results were not significant, $t(26)=-.28, p=$ .78. This hypothesis was not supported.

Hypothesis $3 \mathrm{c}$ stated that individuals who utilize more approach strategies will be less likely to be sexually assaulted during their first semester of college than participants who use fewer approach coping strategies. An independent samples $t$-test compared mean differences on approach coping strategies between the two groups (sexually assaulted and non-assaulted). The results were not significant, $t(25)=-.78, p=.45$. This hypothesis was not supported.

Hypothesis four stated that victims of childhood sexual abuse who have lower levels of forgiveness towards their abuser will be more likely to be sexually assaulted during their first semester of college when compared to victims of childhood sexual abuse who have higher levels of forgiveness towards their abuser. An independent samples $t$-test compared mean differences on levels of forgiveness between the two groups (sexually assaulted and non-assaulted). The results were not significant, $t(8)=.08$, $p=.94$. This hypothesis was not supported.

Hypothesis five stated that victims of childhood sexual abuse who have not disclosed their abuse experiences to at least one other person will be more likely to be sexually assaulted in their first semester of college when compared to victims who had disclosed their childhood abuse experiences to at least one person. The probability of being sexually assaulted (sexually assaulted and non-assaulted) based on disclosure of childhood abuse experiences (have disclosed or have not disclosed) was tested using a 
Chi-Square analysis. The results were not significant, $\mathrm{x}^{2}(1, N=10)=.28, p=.60$. This hypothesis was not supported. 


\section{CHAPTER V}

\section{DISCUSSION}

Research has demonstrated that victims of childhood sexual abuse are at increased risk for being sexually victimized as adults, however, further research is needed to identify specific outcome variables of childhood sexual abuse which help predict this risk of victimization in adulthood. This study aimed to help fill this gap in the literature by examining outcome variables of childhood sexual abuse in the context of the Finkelhor and Browne's (1975) traumagenic dynamics model, which identifies the four main trauma sources resulting from childhood sexual abuse. While many variables investigated in this study were not significantly related to adult revictimization, the results supported the overarching hypothesis that childhood victims of sexual abuse are at an increased risk for sexual revictimization in adulthood, adding support to the existing literature. Of the 167 individuals who participated in Time 1 data collection, 27.6\% (54 individuals) indicated that they had experienced some form of childhood sexual abuse. These rates are quite consistent with other studies investigating childhood sexual abuse experiences of female college students, which have been found to range from $27.6 \%$ to as high as $37.7 \%$ (Aspelmeier et al., 2007; Roche et al., 1999).

This study also found that hypothesis one was supported, which indicates that individuals who had experienced sexual abuse as children were at a higher risk for sexual revictimization in their first semester on a college campus. This finding is consistent with 
literature that suggests that victims of childhood sexual abuse are between 2 to 11 times more likely to be revictimized as adults in comparison to individuals with no history of victimization (Messman-Moore \& Long, 2003). While it is known that college students in general are at an increased risk for sexual assault (DeKeseredy \& Kelly, 1993; Fisher, Cullen, \& Turner, 2000; Koss, Gidycz, \& Wisniewski, 1987), the results of this study suggest that CSA victims may be a subpopulation within this already vulnerable group which is at an even higher risk. In this sample, only individuals who had a history of childhood sexual abuse experienced sexual victimization during their first semester on campus. This information, coupled with the alarming prevalence rates noted above, should indicate to universities that there may be a large population of vulnerable individuals on their campuses. Future research should focus on how universities can tailor their sexual assault interventions and campaigns to more accurately address the needs of this specific population, as they may be at a higher risk.

Additionally, this study had an interesting finding in regards to body image. While not statistically significant, the childhood sexual abuse group had clinically higher rates of body dissatisfaction than the non-abused group. These results are consistent with findings from Kearney-Cooke and Ackard (2000) who also found higher rates of body image dissatisfaction among individuals who had been sexually abused as children. These findings suggest that while body image issues are universal, individuals with a history of childhood sexual abuse may be at a higher risk of developing body image issues. Many college campuses try to focus interventions on body image, such as National Eating Disorder Awareness week, which is celebrated on many campuses across the United 
States. This information could be used by college campuses to more accurately tailor their interventions for this population, especially in regards to training counselors to assess for trauma history when working with student clients who seem to have unrelated issues such as eating disorders or body image dissatisfaction.

While the hypothesis that body dissatisfaction would be related to sexual revictimization in adulthood was not statistically significant, the results were clinically significant. The sexually assaulted freshman women in this sample reported scores which fell in the highest clinical category, "marked concern with shape", while the nonassaulted participants had scores that were much lower, falling into the category of "mild concern with shape" (which is the lowest clinically significant category, above "no concern with shape").

Taking together the results of hypothesis $2 \mathrm{a}$ and $2 \mathrm{~b}$, we find that CSA victims have clinically higher rates of body image dissatisfaction and that body image dissatisfaction was clinically higher among those who had been sexually assault in the first semester of college. It is interesting to note, as well, that all of the individuals who fell into the "marked concern with shape" category were actually CSA victims. Of course, it must be pointed out that these findings come from a low sample size (3 assaulted individuals compared to 25 non-assaulted individuals), so these findings must be viewed with caution and more data should be collected to investigate this further.

A common reaction to experiences of childhood sexual abuse is to develop shame about one's body (Ratican, 1992) as well as a negative body image (Kearney-Cooke \& Ackard, 2000). There is much research which supports the idea that victims of childhood 
sexual abuse engage in dysfunctional sexual behaviors to cope with the distress resulting from their abuse, such as their body image dissatisfaction (Briere, Elliott, Harris, \& Cotman, 1995; Briere \& Runtz, 1990; Briere \& Zaidi, 1989; Runtz \& Roche, 1999; Walser \& Kern, 1996). Additionally, there is plentiful research which demonstrates that these same dysfunctional sexual behaviors exhibited by CSA victims puts them at an increased risk for sexual revictimization (Briere, 1995; Runtz \& Roche, 1999). One may hypothesize that using sex to cope with these negative feelings may be the avenue by which body image affects revictimization rates in individuals with a history of childhood sexual abuse.

Further research should focus on body image dissatisfaction as a potential risk factor for sexual revictimization in adulthood as there are many clinical applications for such data. This data could be especially relevant for college campuses, as this is an arena where individuals are known to suffer from body image issues (Soet \& Sevig, 2006; Vohs, Heatherton, \& Herrin, 2001). If body image dissatisfaction plays a role in the likelihood of sexual assault, then campuses can create campaigns focusing on this factor in the hopes of reducing the occurrence of sexual assault on campus.

The hypothesis that CSA victims and non-victims would differ in terms of coping strategies utilized was not supported. The measure used to assess coping strategies (the Brief COPE) has instructions which prompt the participant to think about the coping strategies they utilize most often rather than the strategies they may use in a particular context. Future research should examine if coping strategies differ when prompting participants to respond with the coping strategies utilized in a specific, overwhelming 
context (in this case, childhood sexual abuse) as opposed to their most used coping strategies. Because sexual abuse is an event that is drastically different than most everyday stressors, it is possible that individuals may utilize different coping approaches when dealing with the negative thoughts and emotions associated with it. One must examine this information in the context of the Transactional Model of Stress and Coping (Lazarus \& Cohen, 1977). This model states that an individual chooses coping strategies on a case-by-case basis, as each unique stressor must be evaluated in terms of its threat to the individual. When an individual examines a stressor and determines that they have the ability and resources to handle it, they are more likely to implement approach strategies as the individual feels the stressor is within their control. Everyday stressors such as school, work, and relationships may seem more controllable as they are encountered frequently and are less severe when compared to the stress of sexual abuse. Future research should investigate if participant answers would differ if they were instructed to respond with the coping strategies they use in a specific context, such as abuse, rather than their most used coping strategies.

The hypotheses that forgiveness levels or disclosure rates of abuse experiences would be related to the probability of sexual revictimization were not supported. This study suffers from the major limitation of low sample sizes and low rates of participants returning for post-test measures. Unfortunately, attrition was high between pre and post test measures, which resulted in low statistical power when examining these hypotheses. The hypothesis that forgiveness or disclosure may be related to the probability of sexual revictimization should be re-examined with a larger participant pool. While it may well 
be true that these variables are not related, it is premature to deem them null when the sample size of assaulted individuals was so small (only three participants).

Limitations of the present study should be noted, the primary of which is a small sample size. Future studies may wish to increase the amount of contact between participants and researchers, utilizing an in-person format rather than an online format in an attempt to reduce participant attrition. Future research should also aim to expand data collection across several college campuses in order to maximize generalizability of the resulting data, as the present study only represents one particular student body. Including multiple colleges may also help to increase the ethnic diversity of the sample, as the current sample was predominantly Caucasian. Future research could also aim to begin Time 2 data collection slightly earlier in the semester than the present study, which will allow researchers more time to send multiple reminder emails to participants (hopefully increasing participation) and avoid Time 2 data collection coinciding with the final exam week of the school, a time at which participants may be less likely to spend time on extracurricular research.

The present study has several implications for individuals with a past history of childhood sexual abuse. This study supports previous literature which finds that CSA victims in particular may be at a higher risk for sexual assault when entering their college career, an arena where individuals are already at a higher risk for sexual assault compared to the general population (DeKeseredy \& Kelly, 1993; Fisher, Cullen, \& Turner, 2000; Koss, Gidycz, \& Wisniewski, 1987). Some research suggests that major outcomes of childhood sexual abuse often may not appear until an individual is confronted with 
developmental tasks associated with these issues, such as the development of sexuality in young adulthood (Briere, 1992). College is often a place where students are confronted with such tasks as developing romantic relationships, exploring sexual identity, and dealing with the sexual advances of others, which may trigger in some CSA victims the memories associated with their sexual abuse experiences. In the present study, only individuals with a past history of CSA reported experiences of sexual assault in their first semester of college. As discussed earlier, childhood sexual abuse can result in dissatisfaction with one's body, (Kearney-Cooke \& Ackard, 2000) which some CSA victims may cope with through risky sexual behaviors, which is known to put them at a higher risk for sexual revictimization (Briere, Elliott, Harris, \& Cotman, 1995; Briere \& Runtz, 1990; Briere \& Zaidi, 1989; Runtz \& Roche, 1999; Walser \& Kern, 1996). All of these factors combine to make college a context wherein CSA victims are at a high risk for revictimization and highlight the importance of further research to identify interventions to protect this vulnerable population. 


\section{REFERENCES}

Alaggia, R. (2005). Disclosing the trauma of child sexual abuse: A gender analysis. Journal of Loss and Trauma, 10 (5),453-470.

Arata, C.M. (1998). To tell or not to tell: Current functioning of child sexual abuse survivors who disclosed their victimization. Child Maltreatment, 3, 63-71.

Ball, V. (2010). Forgiveness and adjustment in women who have experienced trauma. Dissertation Abstracts International: Section B: The Sciences and Engineering, 70(9-B), 2010. 5805.

Briere, J. (1992). Methodological issues in the study of sexual abuse effects. Journal of Consulting \& Clinical Psychology, 60, 192-203.

Briere, J. (2000). Psychotherapy for adult abuse survivors. Paper presented at the 16th Annual Midwest Conference on Child Sexual Abuse and Incest, Middleton, Wisconsin.

Briere, J., Elliott, D. M., Harris, K., \& Cotman, A. (1995). Trauma Symptom Inventory: Psychometrics and association with childhood and adult victimization in a clinical sample. Journal of Interpersonal Violence, 10, 387-401.

Briere, L, \& Runtz, M. (1990). Differential adult symptomology associated with three types of child abuse histories. Child Abuse \& Neglect, 14, 357-364.

Briere, J., \& Zaidi, L. Y. (1989). Sexual abuse histories and sequelae in female psychiatric emergency room patients. American Journal of Psychiatry, 146, 16021606.

Boon, S.D., \& Sulsky, L.M. (1997). Attributions of blame and forgiveness in romantic relationship: A policy-capturing study. Journal of Social Behavior and Personality, 12, 19-44.

Burgess, AW; Holmstrom, LL (1976). Coping behavior of the rape victim. American Journal of Psychiatry, 133(4), 413-8.

Carver, C.S. (1997). You want to measure coping but your protocol's too long: Consider the Brief Cope. International Journal of Behavioral Medicine, 4, 92-100.

Coffey, P; Leitenberg, H; Henning, K; Turner, T; Bennett, R. (1996). Mediators of the long-term impact of child sexual abuse: Percieved stigma, betrayal, powerlessness, and self-blame. Child Abuse and Neglect, 20(5), 447-455.

Cohen, E, \& Lazarus, R. S. (1973). Active coping processes, coping dispositions, and recovery from surgery. Psychosomatic Medicine, 35, 375-389.

Cooper, P.J.; Taylor, M.J.; Cooper, Z.; \& Fairburn. (1986). The development and validation of the Body Shape Questionnaire. International Journal of Eating Disorders, 6, 485-494.

DeKeseredy, W., \& Kelly, K. (1993). The incidence and prevalence of woman abuse in 
Canadaian university and college dating relationships. Journal of Human Justice, 4, 25-52.

Dube, S., Anda, R., Whitfield, C., Brown, D., Felitti, V., Dong, M. \& Giles, W. (2005). Long term consequences of childhood sexual abuse by gender of victim. American Journal of Preventative Medicine, 28(5), 430-438.

Elliott, D.M., \& Briere, J. (1994). Forensic sexual abuse evaluations of older children: Disclosures and symptomatology. Behavioral Sciences and the Law, 12, 261-277.

Finkelhor, D. (1979). Sexually Victimized Children. Jefferson, NC: McFarland \& Company, Inc., Publishers.

Finkelhor, D., \& Browne, A. (1985). The traumatic impact of child sexual abuse: A conceptualization. American Journal of Orthopsychiatry, 66(4), 530-541.

Finkelhor D, Dziuba-Leatherman J (1994). Children as victims of violence: a national survey. Pediatrics, 94, 413-420.

Fisher, B., Cullen, F., and Turner, M. (2000). The sexual victimization of college women: Findings from two national-level studies. Washington, DC: National Institute of Justice and Bureau of Justice Statistics.

Foa, E. B., Zinbarg, R., \& Olasov-Rothbaum, O. (1992). Uncontrollability and unpredictability in post-traumatic stress disorder: An animal model. Psychological Bulletin, 112, 218-238.

Fortier, M; DiLillo, D; Messman-Moore, T; Peugh, J; DeNardi, K; \& Gaffey, K. (2009). Severity of child sexual abuse and revitimization: the mediating role of coping and trauma symptoms. Psychology of Women Quarterly, 33 (3), 308-320.

Ghaderi, A., Scott, B., 2004. The reliability and validity of the Swedish version of the Body Shape Questionnaire. Scandinavian Journal of Psychology, 45, 319-324.

Girard, M., \& Mullet, E. (1997). Propensity to forgive in adolescents, young adults, older adults, and elderly people. Journal of Adult Development, 4, 209-220.

Gorey, K., \& Leslie D (1997). The prevalence of child sexual abuse: integrative review adjustment for potential response and measurement bias. Child Abuse and Neglect, 21, 391-398.

Hebert, Tourigny, Cyr, McDuff, \& Joly. (2009). Prevalence of childhood sexual abuse and timing of disclosure in a representative sample of adults from Quebec. Canadian Journal of Psychiatry, 54(9), 631-636.

Hershkowitz, I., Horowitz, D., Lamb, M. (2005). Trends in children's disclosure of abuse in Israel: a national study. Child Abuse and Neglect, 29(11), 1203-14.

Hight, T. L. (1998). Interpersonal forgiving in close relationships: II. Theoretical elaboration and measurement. Journal of Personality and Social Psychology, 75, $1586-1603$.

Holmes, W.C.; Slap, G.B. (1997). Sexual abuse of boys: Definition, prevalence, correlates, sequelae, and Management. The Journal of the American Medical Association, 280(21), 1855-1862. 
Holohan, C. J., \& Moos, R. H. (1985). Life stress and health: Personality, coping, and family support in stress resistance. Journal of Personality and Social Psychology, 49, 739-747.

Humphrey, J.A. \& White, J.W. (2000). Women's vulnerability to sexual assault from adolescence to young adulthood. Journal of Adolescent Health, 27, 419-424.

Kearney-Cooke AM \& Ackard DM. (2000). The effects of sexual abuse on body image, self image, and sexual activity of women. The Journal of Gender-Specific Medicine, 3(6), 54-60.

Kedall-Tackett, Kathleen, A; Williams, Linda M.; Finkelhor, David. (1993). Impact of sexual abuse on children: A review and synthesis of recent empirical studies. Psychological Bulletin, 113 (1).

Koss, M.P., Gidycz, C.A., and Wisniewski, N. (1987). The scope of rape: Incidence and prevalence of sexual aggression and victimization in a national sample of higher education students. Journal of Counseling and Clinical Psychology, 55(2), $162-70$.

Koss, M. P., \& Oros, C. J. (1982). Sexual experiences survey: a research instrument investigating sexual aggression and victimization. Journal of Consulting and Clinical Psychology, 50, 455-457.

Lanktree, C.B., \& Briere, J. (1995). Outcome of therapy for sexually abused children: A repeated measures study. Child Abuse \& Neglect: The International Journal, 19, 1145-1155.

Lazarus, R. S., \& Folkman, S. (1984). Stress, appraisal, and coping. New York: Springer. McCullough, M. E., Rachal, K. C., Sandage, S. J., Worthington, E. L., Jr., Brown, S. W., \& Hight, T.L. (1998). Interpersonal forgiving in close relationships: II. Theoretical elaboration and measurement. Journal of Personality and Social Psychology, 75, 1586-1603.

McCullough, M. E., Root, L. M., \& Cohen, A. D. (2006). Writing about the benefits of an interpersonal transgression facilitates forgiveness. Journal of Consulting and Clinical Psychology, 74, 887-897.

McCullough, M.E., Pargament, K.I., \& Thoresen, C.E. (2000). The psychology of forgiveness: History, conceptual issues, and overview. In M.E. McCullough, K. I. Pargament, \& C.E. Thoresen (Eds.), Forgiveness: Theory, research, and practice. New York: Guilford Press.

McCullough, M.E., \& Witvliet, C.V.O. (2001). The psychology of forgiveness. In C.R.. Snyder and S. Lopez (Eds.), Handbook of positive psychology, 446-458.

Merrill, L. L., Thomsen, C. J., Sinclair, B. B., Gold, S. R., \& Milner, J. S. (2001). Predicting the impact of child sexual abuse on women: The role of abuse severity, parental support, and coping strategies. Journal of Consulting and Clinical Psychology, 69, 992-1006.

Messman, T.L., \& Long, P.J. (2000). Child sexual abuse and revictimization in the form of adult sexual abuse, adult physical abuse, and adult psychological maltreatment. Journal of Interpersonal Violence, 15 (5).

Messman-Moore, T.L, \& Long, P.J. (2003). The role of childhood sexual abuse sequelae in the sexual revictimization of women: An empirical review and theoretical 
reformulation. Clinical Psychology Review, 23, 537-571

McGee, H., Garavan, R., de Barra, M., Byrne, J., \& Conroy, R. (2002). The SAVI Report: Sexual abuse and violence in Ireland - a national study of Irish experiences, beliefs and attitudes concerning sexual violence. Dublin: The Liffey Press \& Dublin Rape Crisis Centre.

Ohbuchi, K., Kameda, M., \& Agarie, N. (1989). Apology as aggression control: Its role in mediating appraisal of and response to harm. Journal of Personality and Social Psychology, 56(2), 219-227.

Perrott, K., Morris, E., Martin, J., \& Romans, S. (1998). Cognitive coping styles of women sexually abused in childhood: A qualitative study. Child Abuse and Neglect, 22, 1135-1149.

Polusny, M. A., Rosenthal, M. Z., Aban, I., \& Follette, V. M. (2004). Experiential avoidance as a mediator of the effects of adolescent sexual victimization on adult psychological distress. Violence and Victims, 19, 1-12.

Pook M, Brahler E, Tuschen-Caffier B. (2009). Female body dissatisfaction across different age groups: Normative data for the German version of the body shape questionnaire. Verhaltenstherapie, 19(1), 14-20.

Pook, M., Tuschen-Caffier, B., Stich, N., 2002. Evaluation of the German version of the Body Shape Questionnaire. Verhaltenstherapie, 12, 116-124.

Pook, M., Tuschen-Caffier, B., (2004). Sensitivity to change of scales assessing symptoms of bulimia nervosa. Psychiatry Research, 128, 71-78.

Putnam, F. W. (2003). Ten-year research update review: Child sexual abuse. Journal of the American Academy of Child and Adolescent Psychiatry, 42(3): 269-278.

Paine, M. L., \& Hansen, D. J. (2002). Factors influencing children to self-disclose sexual abuse. Clinical Psychology Review, 22(2), 271-295.

Ratican, K. (1992). Sexual abuse survivors: Identifying symptoms and special treatment considerations. Journal of Counseling \& Development, 71(1), 33-38.

Reese-Weber, M. \& Smith, D. M. (2011). Outcomes of child sexual abuse as predictors of later sexual victimization. Journal of Interpersonal Violence, 26(9), 1884-1905.

Rosen, J.C., Jones, A., Ramirez, E., \& Waxman, S. (1996). Body Shape Questionnaire: studies of validity and reliability. International Journal of Eating Disorders, 20, 315-319.

Roth, S., \& Cohen, L. J. (1986). Approach, avoidance, and coping with stress. American Psychologist, 41, 813-819.

Runtz, M. G., \& Roche, D. N. (1999). Validation of the Trauma Symptom Inventory in a Canadian sample of university women. Child Maltreatment, 4, 69-80.

Russell, D. (1986). The secret trauma: Incest in the lives of girls and women. New York: Basic Books.

Sanderson, C. (2006). Counselling Adult Survivors of Child Sexual Abuse. Philadelphia, PA: Jessica Kingsley Publishing.

Siegel, J.A., \& Williams, L.M. (2001). Risk factors for violent victimization of women: A prospective study, final report. Final report submitted to the National Institute of Justice, July 2001, NCJ 189161.

Shapiro, D. L., \& Levendosky, A. A. (1999). Adolescent survivors of childhood sexual 
abuse; The mediating role of attachment style and coping in psychological and interpersonal functioning. Child Abuse and Neglect, 23, 1175-1191.

Slade, P. (1988). Body image in anorexia nervosa. The British Journal of PsychiatrySupplementary Materials, 2.

Soet, J. \& Sevig, T. (2006). Mental health issues facing a diverse sample of college students: Results from the College Student Mental Health Survey. NASPA Journal, 43(3), 410-431.

Sorsoli, L., Kia-Keating, M., \& Grossman, F. K. (2008). "I keep that hush-hush:” Male survivors of sexual abuse and the challenges of disclosure. Journal of Counseling Psychology, 55, 333-345.

Toussaint, L., \& Webb, J. R. (2005). Theoretical and empirical connections between forgiveness, mental health, and well-being. In E. L. Worthington, Jr. (Ed.), Handbook of forgiveness (207-226). New York: Brunner-Routledge.

Ullman, S., \& Filipas, H. (2005). Gender differences in social reactions to abuse disclosures, post-abuse coping, and PTSD of child sexual abuse survivors. Child Abuse \& Neglect, 29, 767-782.

U.S. Department of Health and Human Services, Administration for Children and Families, Administration on Children, Youth and Families, Children's Bureau. (2011). Child Maltreatment 2010. Retrieved from: http://www.acf.hhs.gov/programs/cb/stats_research/index.htm\#can.

U.S. Department of Health and Human Services, Administration for Children and Families, Administration on Children, Youth and Families, Children's Bureau. (2012). Child Maltreatment 2011. Retrieved from: http://www.acf.hhs.gov/programs/cb/research-data-technology/statisticsresearch/child-maltreatment.

U.S. Department of Health and Human Services, Administration for Children and Families, Office of Planning, Research, and Evaluation. (2010). National Incidence Study of Child Abuse and Neglect (NIS-4). Retrieved from: http://www.acf.hhs.gov/programs/opre/research/project/national-incidence-studyof-child-abuse-and-neglect-nis-4-2004-2009.

United States Department of Justice. Bureau of Justice Statistics. National Crime Victimization Survey, 2002 [Record-Type Files]. ICPSR22902-v2. Ann Arbor, MI: Inter-university Consortium for Political and Social Research [distributor], 2008-12-10. doi:10.3886/ICPSR22902.v2

Vohs, K.D., T.F. Heatherton, and M. Herrin, Disordered eating and the transition to college: A prospective study. International Journal of Eating Disorders, 2001. 29(3): p. 280-288.

Walser, R. D., \& Kern, J. M. (1996). Relationships among childhood sexual abuse, sex guilt, and sexual behavior in adult clinical samples. The Journal of Sex Research, 33, 321-326.

Walsh, K., Fortier, M. A., \& DiLillo, D. (2010). Adult coping with childhood sexual abuse: A theoretical and empirical review. Aggression and Violent Behavior, 15, 113.

Wenninger, K., \& Heiman, J. R. (1998). Relating body image to psychological and sexual 
functioning in child sexual abuse survivors. Journal of Traumatic Stress, 11, 543562.

Widom, C.S.; Czaja, S.J.; Dutton, M.A. (2008). Childhood victimization and lifetime revictimization. Child Abuse and Neglect, 32 (8). 